\title{
Thymoma, thymectomy, and occurrence of systemic lupus erythematosus: a commentary article
}

\author{
Sasan Fallahi ${ }^{1,2^{*}}$ \\ ${ }^{1}$ Internal Medicine Division, Baharloo Hospital, Tehran University of Medical Sciences, Tehran, Iran \\ ${ }^{2}$ Rheumatology Research Center, Tehran University of Medical Sciences, Tehran, Iran
}

Keywords: pure red cell aplasia, systemic lupus erythematosus, thymectomy, thymoma.

\section{To the editor}

I read the interesting manuscript entitled "Thymoma and autoimmune diseases" recently written by Jamilloux et al. In their paper, they stated that no characteristics or pathological information can predict the occurrence of an autoimmune disease after a thymectomy [1]. However, I think this opinion may not be extended to all autoimmune diseases. For example, the association of systemic lupus erythematosus (SLE) with thymoma usually occurs in people older than the typical onset age of lupus. The association between thymoma, thymectomy, and SLE has been reported in several papers. Among these reports, pure red cell aplasia (a type of anemia affecting only the precursors to red blood cells in bone marrow) has been associated with thymoma and SLE in some cases [2-5], and in a few cases, SLE has appeared after the occurrence of pure red cell aplasia and thymectomy [2, 3]. Therefore, pure red cell aplasia in the presence of thymoma may be a predictive clinical feature of SLE in future years. This is a topic of interest which should be investigated in future studies. In my opinion, thymectomy should be avoided in patients with thymoma associated with red cell aplasia. Given the immune regulatory role of the thymus, removing it may facilitate the creation or aggravation of lupus in such cases. The appearance of SLE after thymectomy may be due to loss of central tolerance, the accumulation of self-reactive T-cells in peripheral circulation, or the overproduction of antibodies.

\section{Conflicts of interest}

The author declares no conflicts of interest.

\section{References}

1. Jamilloux Y, Frih H, Bernard C, Broussolle C, Petiot P, Girard N, et al. Thymomes et maladies auto-immunes. La Revue de Médecine Interne 2017 Mar 30.

2. Fallahi S, Akbarian M, Dabiri S. Pure red cell aplasia as a presenting feature in systemic lupus erythematosus and association with thymoma, hypothyroidism and hypoparathyroidism: a case report and literature review. Iran J Allergy Asthma Immunol 2014; 13(2): 138-43.

3. Iwadate H, Kobayashi H, Shio K, Noguchi E, Watanabe $\mathrm{K}$, Sasajima T, et al. A case of systemic lupus erythematosus complicated by pure red cell aplasia and idiopathic portal hypertension after thymectomy. Mod Rheumatol 2006; 16(2): 109-12. doi: 10.1007/s10165006-0465-7.
4. Duchmann R, Schwarting A, Poralla T, Meyer zum Büschenfelde KH, Hermann E. Thymoma and pure red cell aplasia in a patient with systemic lupus erythematosus. Scand J Rheumatol 1995; 24(4): 251-4. doi: 10.3109/030097495091008884.

5. Marmont AM, Bacigalupo A, Gualandi F, Bregante S, van Lint MT, Geroldi S. Systemic lupus erythematosus complicated with thymoma and pure red cell aplasia (PCRA). CR of both complications following thymectomy and allogeneic haematopoietic SCT (HSCT), but persistence of antinuclear antibodies (ANA). Bone Marrow Transplant 2014 Jul; 49(7): 9823. doi: 10.1038/bmt.2014.68.

\footnotetext{
* Sasan Fallahi, Email: sfallahi@ sina.tums.ac.ir and drsfallahi@ gmail.com Received: 08 April 2017; Accepted: 15 August 2017
} 